\title{
Psychological Features of Women with Deviating Body Mass Index and Eating Disorders
}

\author{
${ }^{1}$ Natal'ya G. Bazenova, ${ }^{2}$ Oksana V. Tokar, ${ }^{3}$ Elena Yu. Shpakovskaya, ${ }^{4}$ Elena M. Razumova, ${ }^{5}$ Ekaterina E. \\ Ruslyakova, ${ }^{6}$ Oksana P. Chernykh \\ ${ }^{1-5}$ Nosov Magnitogorsk State Technical University, 38 Lenin Avenue, 455000, Chelyabinsk Region, Magnitogorsk, \\ Russia \\ ${ }^{6}$ Moscow University of Finance and Law MFUA, 17/1 Serpukhov Val Str., 115191, Moscow, Russia \\ Email:sqvorez@mail.ru
}

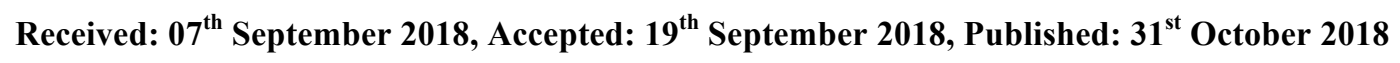

\begin{abstract}
They consider psychological features of women with a deviating body mass index and eating disorders: emotional, restrictive and external. They use psychodiagnostic and statistical methods of research. It is shown that the respondents with a deviating body mass index have different types of eating behavior and their mixed variants; their eating behavior is characterized by an excessive desire for leanness, binge eating, the dissatisfaction with one's own body, perfectionism and interoceptive incompetence. They determine the psychological features of women with eating disorders: a high level of neuroticism, the non-acceptance of the corporal self-image, the sensitivity to the assessments of others in relation to appearance, the prevalence of irrational catastrophization and self-esteem attitudes, low frustration tolerance; the severity of psychological defenses in the form of negation, regression, compensation, substitution, and reactive developments. They showed the effect of identified psychological special features of women with a deviating body mass index on their eating behavior.
\end{abstract}

\section{Keywords}

Food Behavior, Eating Disorders, Anorexia Nervosa, Bulimia, Body Mass Index, Emotional Type of Eating Behavior, Restrictive Type of Eating Behavior, External Type of Eating Behavior, Psychological Defenses, Irrational Attitudes, Body Image

\section{Introduction \\ Introduction to the Problem}

The last decades are characterized by the increase of people with eating disorders and, as the consequence, the deviations in body mass index. On the one hand, the era of the "consumer society" gave birth to the problem of obesity (which means diabetes mellitus, cardiovascular diseases, musculoskeletal disorders), which is now becoming a real epidemic. On the other hand, mass culture forms the cult of a lean body, elegant bodily aesthetics, the correctness of dietary nutrition, which dictates the appropriate style of eating behavior and anorexia and cachexia are its extreme results among the population (and especially among its young part). This publication discusses some of the psychological characteristics that are characteristic of women with a deviating body mass index (hereinafter-BMI) who have different types of eating behavior.

\section{Problem Relevance}

The study of the stated problem is topical due to the need to design and implement the programs for eating disorder prevention and intervention, which is impossible without an in-depth study of this disorder determinants and their psychological mechanisms.

\section{Problem Study}

The disorders of appetite control and dietary stereotypes affect the body constitution most quickly. The traditional measuring criterion for the corporeality is the body mass index. The body mass index is the value that allows to assess the degree of a person's mass and its growth conformity, and thus assess indirectly whether it is inadequate, normal or excessive one. Overweight, most often at its core, has primary eating disorders, leading to a positive energy balance of the body, hypodynamia or endocrine disorders. The reverse option is conditioned by the constitutional features or regular diets and the attempts to reduce weight; by excessive physical loads (Skugarevsky, 2007, pp. 76-85).

Nutritional behavior refers to the value attitude to food and its taking, the stereotype of nutrition under ordinary conditions and in a stress situation, behavior that is oriented toward the image of one's own body, and the activities developing this image (Avedisova, 1999, pp. 6-17). It is common to distinguish the biological aspect (food acts as the means of energy delivery to the body) in eating behavior. This aspect performs homeostatic, relaxing and hedonic function and realized through the system of eating habits that are formed through the assimilation of family, religious, ethnic, media, dietary and other stereotypes in combination with life experience and personal preferences. 
Thus, the second, social, aspect of human eating behavior is included actively here. It performs communicative, cognitive, ritual, compensatory, encouraging, protective and many other functions and is realized against the background of interpersonal communication and socialization. The third, psychological aspect is closely related to two previous ones, and consists in the fact that food becomes the means of many psychological problems solution, from the removal of psychoemotional tension, the normalization of emotional background and ending with the compensation of unmet needs (the need for communication, parental care, etc.), the reward or promotion at the expense of food tastes, the variant of adaptation under adverse social conditions or mental distress (Isaev, 2005, Tumbasova, 2001, Karvasarsky, 1990; Krasnoperova, 1999; Tsivilko, 1999; Kirschbaum, Eremeeva, 2005; Prilenskaya, 2006).

Thus, human food behavior is aimed at the satisfaction of not only biological and physiological, but also psychological and social needs. Nutritional behavior can be considered as one of the indicators of psychological health in general (Gurvich, 1997. pp. 13-25). At the same time, the increase of various eating disorders is observed, from anorexia nervosa to an extreme degree of overeating. As for the age-and-gender prevalence of the problem under consideration, the prevalence of females aged from puberty to adulthood is found here (Turner, 2010, pp. 4461).

The violation of eating behavior is psychogenically caused disturbances in eating, manifested as specific behavioral syndromes. The main signs of eating disorders are the following ones: a clear violation of eating habits; excessive fears of weight gain; significant efforts to control weight; the negation of weight problem importance; significant disturbance of somatic health as the result of impaired eating behavior; the significant violation of psychosocial functioning as the result of impaired eating behavior; the violation of eating behavior is not the consequence of somatic or other mental disorders (Skugarevsky, 2007, pp. 65-112).

Currently, ICD-10 determines a number of eating disorders, among which the main ones are the following: anorexia nervosa, bulimia nervosa and compulsive overeating.

Anorexia nervosa is the refusal to eat at the presence of appetite and physiological need. The main symptoms are the following ones: extremely low body weight (less than $85 \%$ of ideal weight); an intense fear of weight gaining; disturbed body image; an exceptional concentration on the weight problem; the denial of one's own illness. A persistent and an active restriction in food leads to a significant drop in body weight, dystrophic changes of the most important vital organs, somatoendocrine disorders and cachexia (Korkina, 1995; Krylov, 2007; Skugarevsky, 2007). Nervous bulimia is an eating disorder that accompanies anorexia nervosa, or which occurs independently. The main symptoms are the following ones: bouts of uncontrolled overeating; compensatory behavior aimed at body weight control by the use of specific methods (the purification of the gastrointestinal tract through vomiting and laxative intake, diet, starvation and debilitating exercise); disturbed body image; hypertrophied correlation of self-esteem and body weight / figure features; the sense of control loss over food and one's own life. Nervous bulimia is diagnosed if the symptoms are repeated once a week for three months. Unlike the patients suffering from anorexia nervosa, they do not lose weight so quickly, they can weigh slightly less or even slightly more than normal for their height, but their physical condition worsens (Korkina, 1995; Krylov, 2007; Skugarevsky, 2007).

Compulsive (psychogenic) overeating is the violation of eating behavior, consisting in an atypical reaction to stress in the form of overeating, without further attempts to cleanse the digestive tract (as with bulimia). Symptoms: overeating at the absence of hunger feeling; overeating in response to stress, depressed mood, boredom; paroxysmal loss of control over the process of food intake; the desire to eat alone; the desire to hide the fact of overeating; a sense of shame, guilt, disgust after the episode of overeating. The psychopathological symptoms of bulimia and compulsive overeating are also similar, but the patients with compulsive overeating turn to a doctor later, usually with the intention to lose weight. The prevalence of compulsive overeating is $2 \%$.

In our study, we relied not on clinical, but on psychological criteria and the appropriate styles of eating behavior: restrictive, emotional and external. Restrictive style is characterized by deliberate efforts aimed at desired weight achievement or maintaining through self-restriction in nutrition; emotional style differs by the fact that the desire to eat arises in response to negative emotional states, in the case of an external type, the desire to eat is stimulated not by a real sense of hunger, but by sensory stimuli: appearance, smell, food texture, or by the sight of other people eating food (Malkin-Pykh, 2007; Sidorov, 2012, pp. 25-26).

It is possible to identify the relevant psychological causes and the mechanisms of eating disorder occurrence: unsatisfied needs of both lower and higher order trigger the mechanism of some needs compensation at the expense of other needs, in this case, the most accessible ones - the needs for food; stress, anxiety, neuro-psychic tension involve the mechanism of negative feeling and experience leveling due to the pleasure from eating; the loss of control over events, the sense of losing control over a rapidly changing life, make use food and food intake as the most achievable and controlled sources of guaranteed pleasure, stability, and the lack of problems; Finally, dysmorphophobia and dysmorphomania (painful conviction or the fear of an excessive ugly obesity development, the experience of dissatisfaction with the size, the shape, the character and the degree of fatty deposits) lead to unconscious autoaggressive behavior in the nutrition field (Krylov, 2007; Malkina-Pykh, 2007).

During the violation of eating behavior, the physical "I" acts, on the one hand, as a cause, and on the other hand, as the subject of experiments and transformation. Numerous studies prove the leading role of ideas about the body 
scheme and its functions in the development of self-consciousness structure. Nowadays, the image of one's own body is interpreted as the reflection of the person's internal representation system about his own appearance, connected with self-perception and preferences, including thoughts, beliefs and behavioral reactions (Kreslavsky, 2007; Skugarevsky, 2007; Kunitsyna, 2008). The distortion of own body image, refracted through the corresponding (disturbed) eating behavior, manifests itself in two aspects at least. First of all, it is the distorted perception of one's own body (the perceptive component), which is caused by a variety of factors: the emotional state, the attitudes of others, the features of worn clothes, etc. Secondly, it is the subjective dissatisfaction with one's own appearance (an evaluation component), reflecting global subjective dissatisfaction with weight, body shape or its parts; affective distress in relation to appearance (anxiety, dysphoria, discomfort); cognitions (thoughts and beliefs in relation to appearance), avoiding behavior (the avoiding of situations of concern about one's body) (Skugarevsky, 2007, pp. 3664). Thus, in a broader view, the physical "I" includes perceptive (reflecting the adequacy of perception), affective (emotional), cognitive, evaluative, and behavioral components.

As we mentioned already, eating disorders can be considered as one of the types of pathological adaptation, which raises the question about the ways of an individual psychological protection. The purpose of psychological protection is to reduce emotional tension and anxiety and ensure the regulation of behavior direction (Kirschbaum, Eremeeva, 2005, pp. 59-66). Psychological protection is a special regulatory system of personality stabilization, aimed to eliminate or to minimize the feelings of anxiety associated with the awareness of conflict. Everyone prefers certain defenses that become an integral part of his individual style of struggling with difficulties (Belokrylova, Semke, 2001, pp. 23-35). Researchers tend to determine primary (immature, primitive) defenses: isolation (the blocking of unpleasant emotions, the breaking of ties between an event and its emotional coloring), negation (partial or complete ignorance of information incompatible with the prevailing ideas about oneself), omnipotent control (subjective experience of one's power and the influence on the world), primitive idealization (the need to idealize something or someone) and depreciation (the inevitable side of idealization), projective (unconscious rejection of unacceptable thoughts, attitudes, or desires that are attributed to other people in order to shift responsibility for the personal emotions to the world around us) and introjective (suggestibility, vagaries, tendency to confer beliefs, feelings and attitudes of other people without criticism, without trying change them and make "their own" truly) identification and secondary (mature, developed, higher) protection: the displacement (motivated forgetting or ignoring of thoughts, memories, experiences, which allows to avoid internal conflict by actively shutting out of consciousness (forgetting) not the information about some act or event as a whole, but only the true and unacceptable motive of one's behavior), intellectualization (the isolation of affect from the intellect), rationalization (the awareness and the use of only that part of the information, which is acceptable from a reasonable point of view), identification (a kind of projection associated with the unconscious identification with another person and the transfer of the desired feelings and qualities that the other one has) (Korkina, 1995; Kirschbaum, Eremeeva, 2005; Markov, 2006; Malkina-Pykh, 2007).

The factors discussed above are psychological in nature, and, therefore, should be taken into account and may be subjected to psychological effects for the purpose of disturbed eating behavior therapy. It should also be borne in mind that women are more likely to adopt the role of a patient and need individualized professional help (Gurvich, 1998, p. 38).

\section{Hypotheses}

The women with deviating BMI and eating disorders are characterized by a high level of neuroticism, a negative body image, expressed by irrational attitudes, the prevalence of negation and regression in the psychological defense system; these psychological characteristics are the determinants of eating disorders.

\section{Methods}

The study was conducted from March 2015 to December 2016; the main means for primary information collection was the author's online questionnaire. The Internet users who visited social networks and sites devoted to the problems of body weight ("Typical anorexic", "Psychology of anorexia", "Anorexia", "Leanness", "No Extra weight!", "Khudelka", "Diaries of slimming", "Weight Management", "Your coach", "On Libra", etc.) took part in the experiment.

According to the goal and the objectives of the study, we have formed a general sample, which included girls and women at the age of 16 - 30 years (134 people), then 86 subjects were included according to the indicators of full participation. The average age of the respondents was 23 years. In order to confirm the hypothesis of the study, the respondents were differentiated into groups according to the following criteria:

1. The deviation from normal BMI (as an objective indicator of physical status, which has arisen due to disturbed eating behavior).

2. The severity of eating behavior types (emotional, restrictive, external).

When respondents were classified into groups, we relied on the results of "Quetelet mass index" calculation by the following formula: 
$I=\frac{m}{h^{2}}$

where: $\mathrm{m}$ - body weight in kilograms; $\mathrm{h}$ - height in meters $\left(\mathrm{kg} / \mathrm{m}^{2}\right)$.

In the present experiment, the body weight at which BMI makes at least 18.5 and does not exceed 25 is regarded as norm. The obesity is the excess of BMI making 30, and the BMI from 16 to 18.5 indicates body weight deficiency.

To refine the sample, we conducted the study of eating behavior types. Thus, the following samples were generated:

1. Sample A (41 people) - girls and women with BMI within normal limits and with non-expressed types of disturbed eating behavior.

2. Sample B (45 people) - girls and women with BMI abnormalities both for obesity and for weight deficit with pronounced types of disturbed eating behavior.

For a more detailed study of the psychological characteristics of women, sample B was divided into samples B1 and B2:

3. The sample B1 (21 people) - the subjects with BMI above 25 (overweight) and the predominance of external and emotionogenic types of disturbed eating behavior.

4. The sample B2 (24 people) - the subjects with BMI below 18.5 (low body weight) and the predominance of restrictive and emotionogenic types of disturbed eating behavior.

In order to implement the research goal, we used the following series of techniques:

1. Dutch Eating Behavior Questionnaire (DEBQ, 1986), which identifies the types of eating disorders among the subjects (emotional, restrictive, external) (Malkina-Pykh I.G., 2007. pp. 261-265).

2. "Eating Disorder Inventory" (EDI, 1983, D.M. Garner, M.P. Olmstead, J.P. Polivy) (in the adaptation by O.A. Ilchik, S.V. Sivukha, O.A. Skugarevsky, S. Suihy) - to find out the disorders (anorexia nervosa and bulimia) in eating; includes seven scales: the desire for leanness, bulimia, dissatisfaction with the body, inefficiency, perfectionism, the distrust in interpersonal relations, interoceptive incompetence (Ilchik O.A., 2011. pp. 39-50).

3. "Express diagnosis of neuroticism level" (UN) in 1999 in NIPNI named after Bechterev on the basis of "neuroticization" scale of the UNP questionnaire, which determines the level of neuroticism among respondents (Fetiskin N.P. and others, 2002. pp. 399-400).

4. "Diagnostics of psychological protection typologies" (R. Pluchik, G. Kellerman, H.R. Conte, adaptation by E.S. Romanov, L.R. Grebennikov) (Life Style Index, LSI), revealing the leading psychological protection among respondents: negation, displacement, regression, compensation, projection, replacement, intellectualization, reactive formations (Shpakovskaya E.Yu. et al., 2007. pp. 117-124).

5. "The diagnosis of the body image" by I.V. Lybko (on the basis of Brest State University named after A.S. Pushkin, 2008), studying the image of the physical self, the issues of subject personality self-relationship and their self-perception (Lybko I.V., 2008. pp. 5-21).

6. "The method diagnosing the presence and the severity of irrational attitudes" by A. Ellis (the founder of rationally emotional therapy (RET) in 1955) in order to determine the degree of rationality / irrationality of thinking, the presence and the severity of irrational attitudes of respondents, including the following scales: catastrophization, personal obligations and the obligations in respect of others, evaluation attitude (Kamenyukin, Kovpak, 2008. pp. 201-206).

In order to prove the reliability of the obtained results of the study, we also used the methods of mathematical statistics: the identification of differences in the distribution of the trait ( $\mathrm{t}$ - Student's criterion); the revealing of consistency degree concerning the studied measurements of two characteristics (regression analysis).

\section{Main Part}

The comparative analysis of obtained study results using the methodology of "Dutch food behavior questionnaire" in the samples of respondents with normal and deviating BMI showed that there are significant differences in all the scales considered by us (Table 1).

\begin{tabular}{|c|c|c|c|}
\hline \multirow[t]{2}{*}{ Methodology name } & \multirow[t]{2}{*}{ Methodology scales } & \multicolumn{2}{|c|}{ Student's t-criterion } \\
\hline & & $\begin{array}{c}\text { Sample A (BMI norm) and B } \\
\text { (BMI dev.) }\end{array}$ & $\begin{array}{c}\text { Sample B1 } \\
\text { (increased BMI) and } \\
\text { B2 (decreased BMI) }\end{array}$ \\
\hline \multirow{3}{*}{$\begin{array}{l}\text { The Dutch } \\
\text { questionnaire PP }\end{array}$} & Emotiogenic PP & $3,01 * *$ & 1,30 \\
\hline & Restrictive PP & $2,08 *$ & $2,31 *$ \\
\hline & External PP & $2,10 *$ & $2,91 * *$ \\
\hline \multirow{5}{*}{$\begin{array}{l}\text { Eating } \quad \text { Behavior } \\
\text { Assessment Scale }\end{array}$} & Desire for leanness & 1,45 & 0,96 \\
\hline & Bulimia & 1,52 & $2,42 *$ \\
\hline & Dissatisfaction with body & $3,54 * *$ & 1,63 \\
\hline & Inefficiency & $2,27 *$ & $2,15 *$ \\
\hline & Perfectionism & $2,05 *$ & 1,34 \\
\hline
\end{tabular}




\begin{tabular}{|c|c|c|c|}
\hline & $\begin{array}{l}\text { Distrust in interpersonal } \\
\text { relations }\end{array}$ & 1,25 & 1,53 \\
\hline & Interceptive incompetence & $2,58 *$ & $2,06 *$ \\
\hline $\begin{array}{l}\text { Express diagnostics } \\
\text { of UN }\end{array}$ & Neurotization level & $3,26 * *$ & 1,93 \\
\hline \multirow{9}{*}{$\begin{array}{l}\text { Diagnostics of } \\
\text { psychological } \\
\text { defense typologies }\end{array}$} & Negation & $3,57 * *$ & 2,01 \\
\hline & Displacement & 2,01 & 1,84 \\
\hline & Regression & $3,04 * *$ & $2,63^{*}$ \\
\hline & Compensation & $2,71 * *$ & 1,45 \\
\hline & Projection & 1,94 & 2,05 \\
\hline & Substitution & $2,86 * *$ & 1,32 \\
\hline & Intellectualization & 1,25 & 2,03 \\
\hline & Reactive formations & $3,12 * *$ & 0,96 \\
\hline & $\begin{array}{l}\text { Index of psychological } \\
\text { defense intensity }\end{array}$ & $3,42 * *$ & 1,83 \\
\hline \multirow[t]{2}{*}{$\begin{array}{ll}\text { Body } & \text { image } \\
\text { diagnostics } & \end{array}$} & $\begin{array}{l}\text { Self-acceptance of body } \\
\text { image }\end{array}$ & $2,48^{*}$ & 1,48 \\
\hline & $\begin{array}{l}\text { The influence of the other on } \\
\text { the attitude of body image }\end{array}$ & $2,62 *$ & 1,60 \\
\hline \multirow{6}{*}{$\begin{array}{l}\text { The method of } \\
\text { irrational attitude } \\
\text { diagnostics }\end{array}$} & Catastrophization & $3,51 * *$ & 0,82 \\
\hline & Personal obligations & $3,58 * *$ & $2,33^{*}$ \\
\hline & $\begin{array}{l}\text { Obligations in relation to } \\
\text { others }\end{array}$ & $2,35^{*}$ & $2,51 *$ \\
\hline & Low frustration toler. & $2,07 *$ & 2,04 \\
\hline & Self-evaluation & 1,86 & 1,95 \\
\hline & & $\begin{array}{l}* t_{\mathrm{kp}}=2,02 \text { at } \mathrm{p} \leq 0,05 ; * * \mathrm{t}_{\mathrm{kp}}=2,69 \\
\text { at } \mathrm{p} \leq 0,01\end{array}$ & $\begin{array}{l}* \mathrm{t}_{\mathrm{kp}}=2,06 \text { at } \mathrm{p} \leq 0,05 \\
* * \mathrm{t}_{\mathrm{kp}}=2,80 \text { at } \mathrm{p} \leq 0,01\end{array}$ \\
\hline
\end{tabular}

Table 1: Reliability of Differences in Respondent Groups According to Measurable Indicators of Food Behavior, The Level of Neuroticism, Psychological Defenses, The Image of Body and Irrational Attitudes

Thus, according to the scale, an emotive PP for the respondents of the sample B is characterized by eating during stress and by compulsive overeating with emotional discomfort in various life situations, reduced control or the loss of control over food intake, in contrast to sample A, which is more effective in control over effective eating habits, and the intense and anxious emotional state of its respondents provokes uncontrolled eating during problems, finding the way out of the situations by other means. This sample has the average values which are close to normal. The scale of restrictive eating behavior also proved a significant difference between the results of both samples: sample B respondents are characterized by strict control over their weight and food intake, strictness to themselves, control and calorie counting, the ignoring of internal signals for food and water intake, which, according to their opinion, leads to weight loss and can eventually lead to anorexia. In sample A, the values were distributed within the norm for this type of eating behavior, which indicates that the respondents adequately relate to the number of meals and their caloric value. Examining the results according to external PP scale, one can also state a significant difference by the samples under study. The respondents of the sample B often succumb to a large portion or something that looks more appetizing easily and quite often; they can eat with others, even if they have already taken food recently; external stimuli (for example, olfactory) also play a significant role in the nutritional behavior of this sample, in contrast to sample A, whose survey results vary within the limits of the norm.

The analysis of the results for the method "Eating behavior evaluation scale" (Table 1) showed that the respondents of sample B are highly significant: self-evaluation of their body (they are not satisfied with separate parts of the body, which they perceive as "problem zones" and which do not correspond to their image of ideal forms); they do not always understand exactly whether the body is full of food or is still in the stage of hunger; they often experience the feeling of loneliness, helplessness, inner emptiness, the meaninglessness of what is happening; Despite the fact that they are constantly in society, they consider it to be conflict, hostile and unsafe for themselves; There is no sense of security and a general adequacy of their daily life event understanding; they have difficulties in control and making decisions during difficult situations; they show the reluctance and the inability to forgive their shortcomings, they demonstrate perfectionism in relation to the results of their own eating behavior.

At the same time, both samples are similar by a number of indicators, in particular, the respondents of both samples are constantly concerned about their own weight, try to lose weight systematically, resort to diets and caloric value of food, but are inclined to violate an effective diet in respect of overeating, binge eating and purging periodically; They are inclined to limit social contacts, locking themselves up in their problem situations alone and not trusting their surrounding society, which they consider subjectively to be unsafe for themselves. 
The comparative analysis of the results using the method "Express diagnostics of neuroticism level" showed statistically significant differences between the samples, namely, sample B is characterized by an increased level of neuroticism, in which emotional excitability and frustration can be observed in decision-making situations during nutrition, which is accompanied by anxiety, confusion, nervous tension, the centralization of unpleasant psychosomatic sensations and personal flaws, which contributes to the reduction of self-esteem and the desire to communicate with others, which in its turn can lead to the problems of social adaptation. Unlike sample B, sample A shows an undefined level of neuroticism, in which respondents have relative emotional stability with respect to food and nutrition, a more positive mood, the lack of causeless negative feelings, they are more optimistic, more initiative, they implement their goals easier and, thus, they have more stable self-esteem and independence from the surrounding society.

During the performance of "Psychological protection typology diagnostics" the results were obtained showing the similarity between the samples (Table 1). They also use such psychological protections to resolve the issues of effective eating behavior, such as displacement, projection and intellectualization. Both samples are characterized by suppression (in order to avoid internal conflict) of unconscious unacceptable cravings for food, the thoughts and feelings associated with it; the transfer of these impulses to others, their attribution to other people, and, thus, the relieving themselves of responsibility for their feelings. Both samples use the intellectualization mechanism to the least extent, i.e. the respondents suppress the experiences caused by a subjectively unacceptable situation related to food intake very seldom, using logic or manipulative tricks.

The use of such psychological defenses as denial, regression, compensation, substitution and reactive formations is relatively different in these samples. This fact may indicate that the respondents of the sample B are characterized by evasion and the ignoring of potentially dangerous information, "dead-end" and anxious situations associated with a constant correction of body weight to a greater extent; this manifestation of deliberate inattention to obvious information in various spheres of life that may be unpleasant, can threaten self-esteem and social status. They also tend to facilitate the tasks in difficult life situations and use simpler stereotyped ways to get out of a situation, while the behavior can be impulsive, irritable and prone to regression. In order to increase the sense of self-importance, the respondents of the sample B may attempt to find a substitute for their external shortcomings in the form of fantastic positively significant features. The substitution mechanism is also important, which helps to relieve tension, aggression, anger and hostility that have arisen because of an unfulfilled desire by replacing an unacceptable act in an existing situation with an acceptable action.

The analysis of the results using the method "The Diagnosis of the Body Imange" (Table 1) showed that in sample A respondents feel the value of their own body, evaluate it emotionally positively, depend less on the opinions of surrounding people and are more confident in themselves. In the sample B, respondents are less likely to accept their corporal nature and are satisfied with the forms of their body, they want the surrounding people to make more compliments about their appearance, so that their appearance is admirable, i.e. they are dependent on the opinions of others. This indicates that the respondents of this sample have a strong motivation for social approval, and, thus, are conformal and less self-confident.

During the "Diagnostics of irrational attitudes" methodology, the results were obtained demonstrating significant differences between the studied samples for "personal obligations", "catastrophization", "obligations in respect of others" and "low frustration tolerance". Sample B is characterized by a strong belief that they "owe others", which can become the source of stress (including the episodes of overeating or eating restrictions); this condition is aggravated with a regular reminder of their debt, or during the absence of an opportunity to repay the debt. Thus, the situation can be perceived as catastrophic, frustrating, having no way out and bearing an extremely negative nature. In their turn, the respondents of the sample B make demands to the people around them ("everyone is in debt for me"), which can become an even more powerful source of stress; other people meet their expectations very rarely. Thus, when they meet with such a "dead-end" situation, the level of their psychoemotional stress increases, and stress resistance decreases.

Next, let's examine the psychological characteristics under study in comparison between sample B1 (elevated BMI) and B2 (reduced BMI).

The comparative analysis of the results using the "Dutch food questionnaire" method (Table 1) showed that the sample B1 is characterized by an external PP, i.e. they are characterized by overeating "for the company", the inability or the unwillingness to refuse to eat in a state of hunger absence, the arousal of appetite during the visual contact with food, the decrease of self-control over eating behavior. The sample B2 is characterized by a restrictive $\mathrm{PP}$, which is manifested in their thoroughness during calorie content counting at food intake and an excessive severity while limiting himself in the number of meals and its volume; they try to ignore the internal signals of hunger and thirst with the aim of weight reduction or desired weight keeping. There are no statistically significant differences between two samples according to the emotiogenic PP, but at the same time the group of respondents with a higher weight has higher average values, hence, stressful situations can provoke the breakdown in one direction or another.

During the analysis of the results according to the method "The scale of eating behavior evaluation", we obtained reliable differences by the scale "bulimia", "inefficiency" and "interoceptive incompetence" (Table 1). Sample B1 is 
characterized by the presence of overeating episodes, they are more susceptible to the lack of confidence in the feeling of hunger and the saturation of body with food. The respondents of the sample B2 experience the sense of loneliness and alienation from society, the lack of support and security sense.

The analysis of the results according to the method "Diagnostics of psychological protection typologies" revealed that the sample B1 uses the regression mechanism to stabilize its mental well-being more often, i.e. subjecting to frustrating factors, respondents prefer to solve problems more stereotypically, replacing complex tasks with relatively easy and affordable ones, while showing their quick temper and weak emotional-volitional control (Table 1). There were no statistically significant differences between the samples for other psychological protections.

The analysis of the results using the method "The diagnosis of irrational attitudes" showed the number of differences (Table 1). The self-sufficiency characterizes the sample B2, i.e. the statement "I must do something different" can become the source of a stable stressful state and psycho-emotional stress emergence. But sample B1 mainly believes that "all those around them should do something" and, therefore, demonstrates inflated demands, which are not always justified. This fact can provoke emotional stress and, thus, a stressful condition.

There were no significant differences between the B1 and B2 samples for the remaining indicators of the scales under study.

In order to develop a further strategy and the tactics of impact on disturbed eating behavior, we conducted the regression analysis that allowed us to determine the targets of the psychotherapeutic effect (Table 2).

\begin{tabular}{|c|c|c|c|c|c|c|c|c|c|c|}
\hline \multirow[b]{2}{*}{ Scales of methods } & \multicolumn{3}{|c|}{$\begin{array}{c}\text { Dutch questionnaire PP } \\
\text { (scale) }\end{array}$} & \multicolumn{7}{|c|}{$\begin{array}{l}\text { Eating Behavior Assessment Scale } \\
\text { (scales) }\end{array}$} \\
\hline & 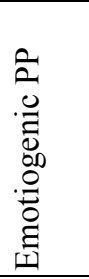 & 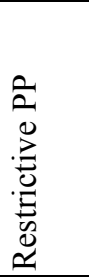 & 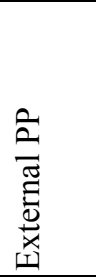 & 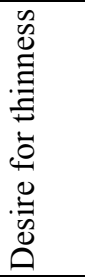 & 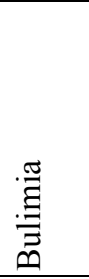 & 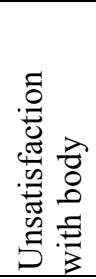 & 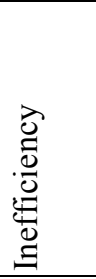 & 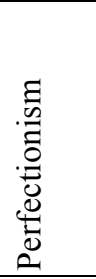 & 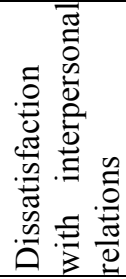 & 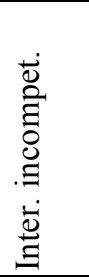 \\
\hline $\begin{array}{ll}\text { Level } & \text { of } \\
\text { neurologization }\end{array}$ & 0,52 & 0,32 & 0,30 & 0,73 & 0,69 & 0,54 & 0,24 & 0,31 & - & - \\
\hline Negation & 0,56 & 0,84 & 0,45 & 0,28 & 0,31 & - & - & - & - & - \\
\hline Regression & - & - & 0,41 & - & 0,64 & - & - & - & - & 0,34 \\
\hline Compensation & 0,64 & 0,48 & - & 0,65 & 0,71 & - & - & 0,68 & & \\
\hline Substitution & 0,72 & 0,61 & - & 0,45 & 0,49 & 0,51 & - & - & - & - \\
\hline Reactive formations & - & - & - & 0,59 & 0,68 & - & - & 0,71 & - & - \\
\hline $\begin{array}{l}\text { Self-acceptance of } \\
\text { corporal image }\end{array}$ & 0,67 & 0,98 & - & 0,31 & 0,43 & 0,52 & - & - & - & - \\
\hline $\begin{array}{l}\text { The influence of } \\
\text { others on the } \\
\text { attitude toward the } \\
\text { corporal image }\end{array}$ & - & 0,68 & - & 0,69 & 0,56 & 0,72 & - & - & - & - \\
\hline Catastrophic nature & 0,79 & 0,68 & 0,58 & 0,52 & 0,45 & 0,76 & 0,65 & - & - & - \\
\hline Personal obligations & 0,65 & 0,72 & - & 0,49 & 0,51 & 0,67 & 0,43 & 0,61 & - & - \\
\hline $\begin{array}{l}\text { Obligations in } \\
\text { relation to others }\end{array}$ & 0,24 & - & 0,15 & 0,31 & 0,37 & $-0,43$ & - & - & - & - \\
\hline $\begin{array}{l}\text { Low frustration } \\
\text { tolerance }\end{array}$ & 0,64 & 0,52 & 0,58 & 0,43 & 0,49 & 0,67 & 0,41 & - & 0,54 & - \\
\hline
\end{tabular}

Table 2: Results of Regression Analysis in the Group with Deviating BMI (Significant Regression Coefficients are Indicated)

In sample B1, regression analysis made it possible to identify the features of neuroticism, psychological defense, the image of the physical self and irrational attitude influence on the assessment of eating disorders among the respondents. Thus, it can be stated that a high level of neuroticism has a significant impact on the emotiogenic PP to a greater extent and on the external one to a lesser extent. At that, this sample also demonstrates the effect of tension, anxiety, and irritability on excessive concern for overweight with frequent episodes of failures (in the form of body cleansing or overeating), the perception of your body and its parts as "problematic and fat", which is accompanied by a sense of estrangement from others and inner loneliness. And in the sample B2, this situation is exacerbated by perfectionism in the form of unwillingness and inability to forgive oneself of shortcomings, overstated requirements to oneself. 
Denial, as a psychological defense, affects the restrictive behavior, the desire for leanness and bulimia in both samples, while also increasing the indicators for both emotiogenic PP and external PP. Behavioral manifestations of the transition to the earlier stages of development (regression) among the respondents of the sample B2 significantly affect the expressed external PP, and the respondents of the sample B1 for the stimulation of appetite, uncertainty in the recognition of hunger and saturation of the organism and, as a consequence, frequent overeating. The frequent use of compensation and hypercompensation mechanisms in a combined B sample significantly affects the manifestation of emotiogenic PP and restrictive PP with systematic attempts to lose weight, use different diets, and at the same time with the episodes of frustration and the inability to forgive these situations. The more respondents use the replacement mechanism, the more often we can state an emotiogenic PP and a restrictive PP with the feeling of dissatisfaction with one's body, a constant desire for leanness with the episodes of purification and overeating. Low rates of acceptance of oneself and the feeling of sympathy for oneself, the unwillingness to listen to information that comes from inside the body, leads, first of all, to restrictive PP, the dissatisfaction with your body as a whole and its separate parts, and an insistent desire to reduce your real weight. A high level of emotional attitude dependence and the evaluation of one's own body on the evaluation of the nearest environment of sample B significantly affects the abuse of diets for weight reduction and a persistent feeling of dissatisfaction with your body. A restrictive PP is characteristic for the respondents with a reduced weight, especially at the initial stages of deviation development, in contrast to the respondents with elevated BMI. A steady dependence on the opinions of others in this sample can become a trigger mechanism for eating disorders.

The results of the research demonstrate that the respondents of all identified types of eating behavior are characterized by the catastrophe of life situations, namely, the dissatisfaction with the body, the desire for thinness, bulimia, the sense of estrangement from others and loneliness, but to a greater extent this characteristic is manifested among the respondents with emotiogenic PP. High rates of "personal obligations" are more likely to be manifested among the respondents with restrictive PP and emotiogenic PP, and can reach the highest point of perfectionism. The feeling that "others owe me constantly" leads to a more frequent finding among the respondents with emotiogenic PP and external PP. At the same time, the more respondents are inclined to "expect from others", blame them for their failures and problems, the lower their dissatisfaction with the body. In general, almost equally all respondents with deviant eating behavior (sample B), are characterized by a low level of stress resistance regardless of eating behavior type.

The psychological features of women with disturbed eating behavior, obtained during the ascertaining stage of the experiment, allowed them to develop the program of psychological assistance "In harmony with themselves", which provides for the complex implementation of various forms of work aimed at cognitive, emotional and behavioral sphere change of woman psyche with impaired food behavior: the formation of knowledge and habits of healthy nutrition with a dietitian; body-oriented therapy, rational-emotional therapy. The experience of the program implementation will be presented in subsequent publications.

\section{Conclusion}

Nutritional behavior of respondents with deviant BMI is characterized by excessive desire for leanness, binge eating, the dissatisfaction with one's own body, personal inefficiency, perfectionism and interoceptive incompetence. They are characterized by a high level of neuroticism, the non-acceptance of the personal body image, the sensitivity to the assessments of others in relation to appearance, the prevalence of irrational catastrophic attitudes, personal obligations and obligations in relation to others, and low frustration tolerance. These respondents have a pronounced psychological defenses of denial, regression, compensation, substitution, and reactive formations.

The respondents with an elevated BMI and eating disorders are characterized by the prevalence of bulimic seizures, interoceptive incompetence and compulsion towards others; they often use regression as a psychological defense.

The respondents with reduced BMI and eating disorders are characterized by personal inefficiency and selfindulgence.

These psychological characteristics are the determinants of eating disorders. All types are affected by a high level of neuroticism, psychological defense of negation, irrational settings of catastrophization and low frustration tolerance without an exception. At the same time, emotionogenic PP is also affected by compensation and substitution, selfacceptance of body image and irrational attitudes towards oneself and others. Restrictive PP - compensation and substitution, as well as the sensitivity to the influence of others in relation to the personal body image and an irrational setting to personal obligations. In respect of external PP: regression and irrational attitude of duty in relation to others.

The revealed tendencies allowed to outline the targets of psychotherapeutic influence: irrational attitudes; psychoemotional stress; the acceptance of personal body image; psychological protection.

\section{Conflict of Interest}

The authors confirm that the presented data do not contain a conflict of interest. 


\section{References}

1. Avedisova A.S. The features of psychopharmacotherapy with borderline mental disorders // Author's abstract from the diss. for the degree of Medical Science Doctor. M. 1999. 54 p. [in Russian].

2. Bazhenova N.G. Psychology of work activity. Course of lectures / N.G. Bazhenova, E.Yu. Shpakovskaya, T.T. Zimareva, O.P. Stepanova, E.I. Shuleva. - Magnitogorsk, 2015. 161 p. [in Russian].

3. Belokrylova M.F., Semke V.Ya. Attachment. Addiction. Symbiosis. Tomsk, 2001. 104 p. [in Russian].

4. Voznesenskaya T.G., Safonova V.A., Platonova N.M. Disturbance of eating behavior and comorbid syndromes during obesity and the methods of their correction // Journal of Neurology and Psychiatry. S.S. Korsakov. 2000. № 12. pp. 49-52. [in Russian].

5. Gavrilov M.A. Interrelation of psychological and physiological features during the normalization of body weight among women who are overweight: abstract from the diss. for the degree of Medical Science Doctor. 1999. 24 p. [in Russian].

6. Gurvich I.N. Social psychology of health. Abstract from the diss. for the degree of Psychology Doctor. St. Petersburg. 1997. 42 p. [in Russian].

7. Isaev D.N. Emotional stress, psychosomatic and somatopsychic disorders among children. SPb., 2005. 400 p. [in Russian].

8. Ilchik O.A. Russian-language adaptation of "Eating behavior assessment scale" methodology / O.A. Ilchik, S.V. Sivukha, O.A. Skugarevsky // Psychiatry, psychotherapy and clinical psychology. 2011. № 1. pp. 3950. [in Russian].

9. Kamenyukin A.G., Kovpak D.V. Anti-stress training. SPb., 2008. pp. 201-205 [in Russian].

10. Karvasarsky B.D. Neuroses. M.: Medicine, 1990. 573 p. [in Russian].

11. Kirschbaum E., Eremeeva A. Psychological protection // 3rd ed. - St. Petersburg, 2005. 176 p. [in Russian].

12. Korkina M.V., Lakosina N.D., Lichko A.E. Psychiatry. M., 1995. 608 p. [in Russian].

13. Korkina M.V., Tsivilko M.A., Kareva M.A. Stages of anorexia nervosa patient rehabilitation. // Social and Clinical Psychiatry. 1993. №1. pp. 84-96 [in Russian].

14. Kreslavsky E.S. Excess body weight and the image of the physical self // Questions of psychology. 2007. № 2.27 p. [in Russian].

15. Krasnopyorova N.Yu. Nutritional addiction and eating disorders: The modern view of the problem // Siberian Herald of Psychiatry and Narcology. 1999. № 2-3. pp. 93-101 [in Russian].

16. Krylov V.I. Psychopathology of eating behavior: anorexia nervosa and bulimia nervosa // Psychiatry and psychopharmacotherapy. 2007. V.9. № 2. [in Russian].

17. Kultyshev D.V. Clinic, dynamics and systematics of borderline disorders among the adolescents with dependent eating behavior. Author's abstract from the diss. for the degree of Medical Science Doctor. Tyumen. 2010. 24 p. [in Russian].

18. Kunitsyna V.N. To the question of body image development among teenagers // The issues of psychology. 2008. № 1. pp. 91-98 [in Russian].

19. Lowen A. Bioenergetics (revolutionary therapy that uses body language to treat the problems of mind) / translation from English. St. Petersburg, 1998. 382 p. [in Russian].

20. Lybko I.V. The method of body image diagnosing // Psychological diagnostics, 2008. № 3. pp. 5 - 21. [in Russian].

21. Malkina-Pykh I.G. Eating behavior. Moscow, 2007. 1040 p. [in Russian].

22. Marilov V.V. The role of psychotherapy in complex treatment of patients with anorexia nervosa // The problems of theoretical and clinical medicine in developing countries. M.: 1995 [in Russian].

23. Markov A.A. Borderline neuropsychiatric disorders with excess weight and obesity. Author's abstract from the diss. for the degree of Medical Science Doctor. - Tomsk, 2006. 23 p. [in Russian].

24. International Classification of Diseases (10-th revision) "Mental and behavioral disorders", adaptation for Russian Federation. - M., 1998. 512 p. [in Russian].

25. Mendelevich V.D. Disorders of dependent behavior (to the formulation of the problem) // Russian Psychiatric Journal. 2003. № 1.pp. 5-9 [in Russian].

26. Miserne R.V. Mental dependence on food as an object of psychotherapy // Herald of Hypnology and Psychotherapy. 2003. № 2. 35 p. [in Russian].

27. Workshop on social psychology / E.Yu. Shpakovskaya, O.P. Stepanova, N.G. Bazhenova, T.T. Zimarev, M.V. Kostyuchenko. Magnitogorsk, 2007. 164 p. [in Russian].

28. Prilenskaya A.V. Analysis and rehabilitation of persons with dependent eating behavior / A.V. Prilenskaya, B.Yu. Prilensky // Siberian Herald of Psychiatry and Narcology. - 2006. Appendix (41). pp. 228-229 [in Russian].

29. Prilenskaya A.V. System approach in the psychotherapy of borderline disorders / B.Yu. Prilensky, A.V. Prilenskaya, M.A. Bogdanovich, I.I. Fedorova, D.V. Kultyshev, I.V. Ovchinnikova, S.O. Sazonov // Monitoring of the psycho. health. Materials from interregional scientific and practical conf. Tomsk; Novokuznetsk, 2006. pp. 139-143 [in Russian]. 
30. Prilenskaya A.V. Boundary neuropsychiatric disorders among the patients with dependent eating behavior (clinical and rehabilitation aspect). Diss. for the degree of Medical Science Doctor. Tomsk. 2009. 163 p. [in Russian].

31. Psychotherapy: the textbook / ed. by V.K. Shamrey, V.I. Kurpatov. - 2nd ed., corrected and added. SPb., 2017. 501 p. [in Russian].

32. Rotov A.V. Dependence of overweight decrease in the process of psychotherapeutic correction from the hypnosis of patients // Siberian Herald of Psychiatry and Narcology. 2000. № 4. pp. 69-71 [in Russian].

33. Rybalko M.I. Polimodal bodily-oriented psychotherapy in the treatment of anorexia nervosa // Act. aspects of psychosomatic research. Tomsk, 2005. pp. 166-168 [in Russian].

34. Sidorov A.V. Eating behaviors and psychological characteristics of weight loss program clients with alimentary obesity. Author diss. for the degree of Psychology Doctor SPb., 2012. 26 p. [in Russian].

35. Skugarevsky O.A. Eating disorders: monograph. Minsk, 2007. 340 p. [in Russian].

36. Taton Y. Obesity: pathophysiology, diagnosis, treatment. M.: 2008. 23 pp. [in Russian].

37. Tokar O.V. Developmental psychology in diagrams, tables, comments: educational-methodical manual. Magnitogorsk, 2010. 63 p. [in Russian].

38. Tumbasova E.R. The analysis of "food behavior" concept // Modern trends in the development of science and technology. 2017. № 3-9. pp. 130-133. [in Russian].

39. Fedorova I.I. Clinical-dynamic and psychotherapeutic aspects of eating disorders. Author's abstract from the diss. for the degree of Medical Science Doctor. Tomsk. 2007. 23 p. [in Russian].

40. Fetiskin N.P., Kozlov V.V., Manuilov G.M. Socio-psychological diagnosis of personality and small groups. - M., 2002. 490 p. - M., 2002. 490 p. [in Russian].

41. Tsivilko M.A., Dmitrieva T.N., Zanozin A.V. The prevalence of anorexia nervosa among urban population // Journal of Neuropathology and Psychiatry. 1999. №3. pp. 24-26 [in Russian].

42. Ellis A. Revision of rational-emotional therapy fundamentals // Evolution of psychotherapy: Collection of articles. V. 2. Autumn of the Patriarchs: psychoanalytically oriented and cognitive-behavioral therapy / Ed. by J.K. Zeiga / Trans. from English. - Moscow: Independent firm "Klass", 1998. 416 p. [in Russian].

43. Ellis A. Rational psychotherapy / A. Ellis // The techniques of psychotherapy and counseling. Texts / ed. and compiled by U.S. Sahakian / translation from English. Moscow: April Press, EKSMO-Press, 2000. pp. 256-276. [in Russian].

44. Yaremenko L.N. Psychoemotional correction during the complex treatment of obesity // Family doctor. 2002. № 2. pp. 35-39 [in Russian].

45. Beck A.T. Cognitive therapy and the emotional disorders. - New-York: International Universities Press, 1976. 356 S. [ in English].

46. Geist R, Heineman M, Stephens D Et al. Comparison of family therapy and family group psychoeducation in adolescents with anorexia nervosa. Can J Psychiatry 2000. S. 173-178 [ in English].

47. Ellis A.A. Overcoming Destructive Beliefs, Feelings, and Behaviors: New Directions for Rational Emotive Behavior Therapy; Prometheus Books. 2001. 419 S. [ in English].

48. Merphy R., Straebler S., Cooper Z. Cognitive behavioral therapy for eating disorders // Psychiatrie Clinics of North America. - 2010. - № 33(3). - S. 611-627. [ in English].

49. Minuchin S. Rosman B.L. \& Baker L. Psychosomatic families" Anorexia Nervosa in context. Cambridge, MA: Harvard University Press. 1978. 315 S. [ in English]. 